\title{
Representative trust and reciprocity: prevalence and determinants
}

Citation for published version (APA):

Dohmen, T. J., Falk, A., Huffman, D., \& Sunde, U. (2008). Representative trust and reciprocity: prevalence and determinants. Economic Inquiry, 46(1), 84-90. https://doi.org/10.1111/j.1465-7295.2007.00082.x

Document status and date:

Published: 01/01/2008

DOI:

10.1111/j.1465-7295.2007.00082.x

Document Version:

Publisher's PDF, also known as Version of record

\section{Please check the document version of this publication:}

- A submitted manuscript is the version of the article upon submission and before peer-review. There can be important differences between the submitted version and the official published version of record.

People interested in the research are advised to contact the author for the final version of the publication, or visit the DOI to the publisher's website.

- The final author version and the galley proof are versions of the publication after peer review.

- The final published version features the final layout of the paper including the volume, issue and page numbers.

Link to publication

\footnotetext{
General rights rights.

- You may freely distribute the URL identifying the publication in the public portal. please follow below link for the End User Agreement:

www.umlib.nl/taverne-license

Take down policy

If you believe that this document breaches copyright please contact us at:

repository@maastrichtuniversity.nl

providing details and we will investigate your claim.
}

Copyright and moral rights for the publications made accessible in the public portal are retained by the authors and/or other copyright owners and it is a condition of accessing publications that users recognise and abide by the legal requirements associated with these

- Users may download and print one copy of any publication from the public portal for the purpose of private study or research.

- You may not further distribute the material or use it for any profit-making activity or commercial gain

If the publication is distributed under the terms of Article $25 \mathrm{fa}$ of the Dutch Copyright Act, indicated by the "Taverne" license above, 


\title{
REPRESENTATIVE TRUST AND RECIPROCITY: PREVALENCE AND DETERMINANTS
}

\author{
THOMAS DOHMEN, ARMIN FALK, DAVID HUFFMAN and UWE SUNDE*
}

\begin{abstract}
This paper provides evidence about the determinants of trust and reciprocal inclinations, that is, a tendency for people to respond in kind to hostile or kind actions, in a representative setting. We investigate the prevalence of reciprocity in the population, the correlation between trust and positive and negative reciprocal inclinations within person, the individual determinants of reciprocity, and the relationship with psychological measures of personality. We find that most people state reciprocal inclinations, in particular in terms of positive reciprocity, as well as substantial heterogeneity in the degree of trust and reciprocity. Trust and positive reciprocity are only weakly correlated, while trust and negative reciprocity exhibit a negative correlation. In terms of determinants, being female and increasing age are associated with stronger positive and weaker negative reciprocal tendencies. Taller people are more positively reciprocal, but height has no impact on negative reciprocity. Psychological traits also affect trust and reciprocity. (JEL D63, J3, J6)
\end{abstract}

\section{INTRODUCTION}

Numerous experiments show that in certain situations people are willing to trust, that is, make themselves vulnerable to exploitation by opportunistic individuals (for a survey, see Camerer 2003). Another large body of experimental evidence documents the tendency for people to be positively reciprocal, rewarding kind actions by others, or be negatively reciprocal, punishing others for unkind actions, even when these reciprocal actions are costly and contrary to own material selfinterest (for a survey, see Fehr and Gächter

*We thank the German Science Foundation for financial support through SPP1169 (Potential for more Flexibility on Heterogeneous Labor Markets).

Dohmen: Senior Research Associate, Institute for the Study of Labor (IZA), P.O. Box 7240, D-53072 Bonn, Germany. Phone 49-228-3894-112, Fax 49-228-3894180, E-mail dohmen@iza.org

Falk: Professor, University of Bonn and IZA, Adenauerallee 24-42, D-53113 Bonn, Germany. Phone 49-228-735082, Fax 49-228-739239, E-mail armin.falk@uni-bonn.de

Huffman: Senior Research Associate, Institute for the Study of Labor (IZA), P.O. Box 7240, D-53072 Bonn, Germany. Phone 49-228-3894-522, Fax 49-228-3894-180, E-mail huffman@iza.org

Sunde: Senior Research Associate, Institute for the Study of Labor (IZA) and CEPR, P.O. Box 7240, D-53072 Bonn, Germany. Phone 49-228-3894-221, Fax +49-228-3894180, E-mail sunde@iza.org
2002). There is little evidence, however, on the prevalence and determinants of these traits in the general population. Exploring these issues requires leaving the laboratory and using a large, representative survey that includes measures of trust, positive reciprocity, and negative reciprocity. In this paper, we pursue this line of research using data from a representative survey of roughly 22,000 adults living in Germany. Information on trust and reciprocal tendencies is accompanied by extensive socioeconomic information and also by psychometric measures of an individual's personality type (the so-called "Big Five").

Our first set of results comes from a comparison of the distributions for trust, positively reciprocal inclinations, and negatively reciprocal inclinations. Our findings indicate substantial heterogeneity in trust, consistent with previous survey evidence on trust (e.g., Alesina and Ferrara 2002; Bellemare and Kröger 2006). To our knowledge, ours is the first evidence from a large survey on the prevalence of negative and positive reciprocity. The prevalence

\section{ABBREVIATION}

SOEP: German Socio-Economic Panel 
of reciprocal types in the population, however, is one crucial factor for predicting the impact of institutions and whether reciprocal or selfish types dominate market equilibrium outcomes (see, e.g., Falk and Fischbacher 2006). We find that moderate to strong positive reciprocity is the norm, whereas negative reciprocity is relatively more heterogeneous.

We next explore how trust and reciprocity are related. Positive reciprocity and negative reciprocity turn out to be only weakly correlated for individuals, which suggests that these are distinct traits rather than two sides of the same coin. This finding is relevant for models of fairness preferences. We also find that people who are strongly negatively reciprocal are less willing to trust. This is consistent with negatively reciprocal types being those who are most upset by betrayal. It implies that while negatively reciprocal individuals may contribute to a climate of trust in a population, by credibly threatening to punish opportunistic norm violators (see the discussion in Fehr and Gächter 2002), they may be less trusting themselves. We find only a very weak positive correlation between trust and positive reciprocity. Thus, people who trust are not necessarily those who are trustworthy.

We also investigate determinants of individual differences in trust and reciprocity, focusing on factors that are exogenous to the individual: gender, age, and height. These characteristics have a significant impact on trust and reciprocity, but the effects vary in interesting ways, providing further indication that these are distinct traits. The exogenous factors remain significant when we control for a wide variety of other observable characteristics. Finally, we provide the first survey evidence on how trust, positive reciprocity, and negative reciprocity relate to personality type, as measured by the standard Big Five scale from psychology. Mapping personality measures from psychology into measures of economic preferences is an important but largely unexplored avenue for research on economic decision making (Heckman, Stixrud, and Urzua 2006). We find that the psychometric measures do have predictive power for both trust and reciprocity.

The next section describes the data. Section III presents results on prevalence and the relationship between trust and reciprocity. Section IV explores determinants of social preferences, and Section V concludes.

\section{DATA}

Our data come from the 2003 and 2005 waves of the German Socio-Economic Panel (SOEP). The SOEP is a representative panel survey of the resident population of Germany. ${ }^{1}$ The SOEP surveys the head of each household in the sample but also gives the full survey to all other household members over the age of 17. Respondents are asked for a wide range of personal and household information and for their attitudes on assorted topics.

In the 2003 wave, the SOEP survey included three questions about individuals' trust attitudes. These are similar to the standard measures of trust used in other surveys, for example, the General Social Survey. Subjects were asked to indicate on a 4-point scale to what extent they agree or disagree with the following statements: ${ }^{2}$ (a) In general, one can trust people; (b) These days you cannot rely on anybody else; and (c) When dealing with strangers it is better to be careful before you trust them. The four answer categories were labeled: strongly agree, agree somewhat, disagree somewhat, and strongly disagree.

In the 2005 wave of the survey, six different measures of reciprocity were included in the SOEP for the first time. Respondents were asked to indicate on a 7-point scale how well each of the following six statements (translated from German) applies to them personally: ${ }^{3}$ (1) If someone does me a favor, I am prepared to return it; (2) If I suffer a serious wrong, I will take revenge as soon as possible, no matter what the cost; (3) If somebody puts me in a difficult position, I will do the same to him/her; (4) I go out of my way to help somebody who has been kind to me before; (5) If somebody insults me, I will insult him/her back; (6) I am ready to undergo personal costs to help somebody who helped me before. An answer of 1 on the scale means: "does not apply to me at all" and choosing 7 means: "applies to me perfectly." Importantly, Questions (1), (4), and (6) ask about positive reciprocity, while

1. For more details on the SOEP, see www.diw.de/ gsoep/.

2. German versions of all six questions are available online, at the following Web site: www.diw.de/deutsch/sop/ service/fragen/fr2003/personen_2003.pdf.

3. German versions of all six questions are available online, at the following Web site: www.diw.de/deutsch/sop/ service/fragen/fr2005/personen_2005.pdf. 
Questions (2), (3), and (5) ask about negative reciprocity. Also, two of the questions ask explicitly whether the respondent would incur costs in order to be negatively reciprocal (Question 2) or positively reciprocal (Question 6). In total, 22,420 individuals responded to all three trust questions, and 20,774 individuals responded to all six reciprocity measures. ${ }^{4}$

We simplify the analysis by collapsing our multiple measures into three indices, which capture an individual's overall inclination to trust, be positively reciprocal, or be negatively reciprocal, respectively. This is accomplished using principal component analysis to combine the information from the three separate measures of each trait (i.e., Statements (a), (b), and (c) for trust, Statements (1), (4), and (6) for positive reciprocity, and Statements (2), (3), and (5) for negative reciprocity) into a scalar measure. ${ }^{5}$ An individual's principal component measure is then obtained by multiplying the standardized answers to the respective questions with the loadings of the questions on the principal component. For comparability across measures, we standardize each of the three principal component measures. In addition to simplifying the analysis, taking the principal component as a measure of trust has an added benefit in terms of behavioral validity, because this measure has been tested previously in a large-scale field experiment and shown to reliably predict actual trusting behavior. ${ }^{6}$ For our measures of reciprocity, a validation in a large-scale field experiment has not yet been conducted.

4. The response rate is very high and quite similar across the individual questions. For each question, we observe responses from at least $99 \%$ of the participants in the respective wave. The loss of observations from 2003 to 2005 is attributed to panel attrition.

5. Principal components analysis allows us to capture the essential variation of the responses and to use this in regression analysis across individuals. We obtain the principal component without rotation. Analysis of eigenvalues shows that for each of the traits, only the principal component from the three underlying measures exhibits an eigenvalue larger than unity. Our results are unchanged if we use factor analysis instead of principal components analysis for all regressions.

6. Fehr et al. (2003) conducted a paid trust game as part of a field experiment with a representative sample of 429 German adults. Subjects also answered the three exact trust measures that are used in our paper. They found that the survey questions reliably predict trusting behavior in the experiment. Other studies have conducted trust games with large representative samples, in different countries, and have shown that similar trust questions are also behaviorally valid.
An important question that has not been addressed is whether constructs from psychology, designed to measure personality type, predict trust and reciprocity, perhaps because they capture some of the primitives underlying these traits. In order to investigate this issue, we use measures of psychological traits building on the concept of the Big Five. The Big Five approach originates in the psycholexical and differential-clinical tradition of personality research and uses respondents' self-assessment in terms of agreement to certain adjectives to describe their personality (see, e.g., Goldberg 1992). The 2005 wave of the SOEP contains a short version of this personality test (see Gerlitz and Schupp 2005, on the implementation and reliability of this measure). Based on this test, each respondent's personality can be described in terms of five traits: conscientiousness, extraversion, agreeableness, openness to new experiences, and neuroticism.

\section{PREVALENCE OF TRUST AND RECIPROCITY}

Our data allow us to compare the prevalence of trust, positive reciprocity, and negative reciprocity in the population. Figure 1 shows the distributions for each of these traits, based on the standardized, principal component measures. A first observation is that there is substantial heterogeneity in trust (see Figure 1a). The distribution is symmetric and exhibits relatively large dispersion around the mean value. In contrast, Figure 1b shows that the distribution for positive reciprocity is strongly left-skewed. This reflects the fact that the modal response is complete agreement, for the three individual statements underlying the principal component, and that few people report complete disagreement that they are positively reciprocal. For negative reciprocity, the distribution is somewhat right-skewed. This reflects the fact that distributions for the underlying measures are closer to uniform, with people reporting levels of agreement all over the scale; the modal response is complete disagreement, but a substantial number choose intermediate values or even the strongest category of agreement with the statements. Overall, the data suggest that there is substantial variation in the degree to which individuals trust. Moderate to strong positive reciprocity is the norm, whereas there is wider variation in the intensity of negatively reciprocal inclinations. 


\section{FIGURE 1}

The Prevalence of Trust and Reciprocity

(a) Prevalence of Trust

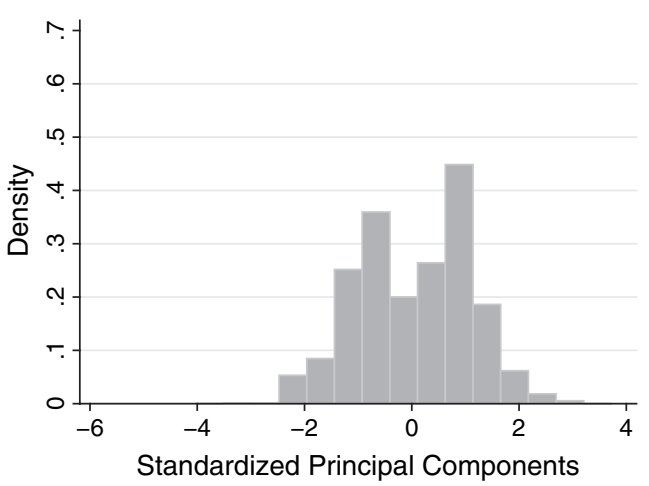

(b) Prevalence of Positive Reciprocity

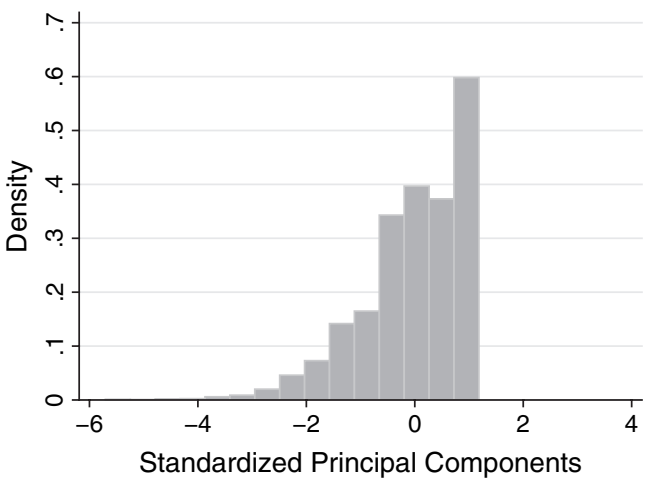

(c) Prevalence of Negative Reciprocity

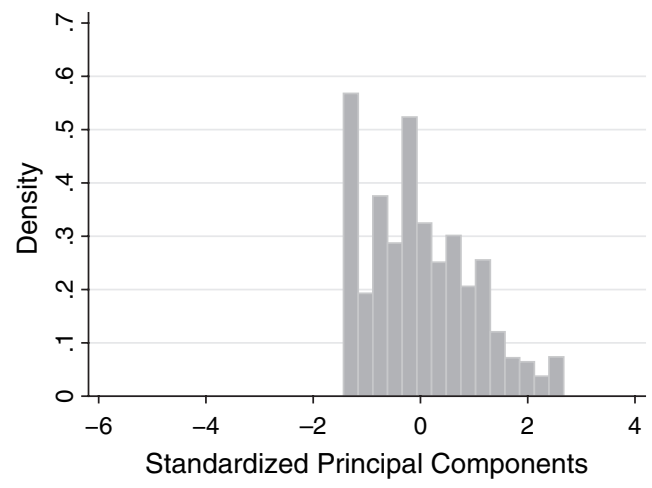

An interesting question is the extent to which positive and negative reciprocity are correlated for an individual. It could be that the degree of someone's positively reciprocal tendencies is a good predictor of their negatively reciprocal tendencies. This would be true if both traits are reflections of the same underlying trait, that is, a tendency to respond in kind. On the other hand, it could be that these are distinct traits, which are uncorrelated or even negatively correlated. Answering this question is important for theoretical models of fairness of preferences. For example, the model of difference aversion proposed by Fehr and Schmidt (1999) has a parameter $\alpha$ describing the intensity of an individual's negatively reciprocal inclinations and a parameter $\beta$ describing the intensity of positively reciprocal inclinations. The empirical question is whether knowing one of these parameters conveys information about the other parameter. There is some experimental evidence hinting at the possibility that positive and negative reciprocity might have different roots. ${ }^{7}$ In our data, we find some additional evidence to support this hypothesis: the correlation between positive and negative reciprocity for an individual is very small, only 0.021 , statistically significant at the $5 \%$ level. Although speculative, one possibility is that negative and positive reciprocity are different because they tap into different emotional responses. ${ }^{8}$

7. For example, positive reciprocity tends to be weaker than negative reciprocity in laboratory experiments (e.g., see Abbink, Irlenbusch, and Renner 2000).

8. For instance, anger appears to be important for explaining punishment behavior in experiments (Fehr and Gächter 2002). There is less evidence on the specific emotions involved in positive reciprocity, but candidates include gratitude or possibly anticipated guilt associated with not rewarding. 
We can also investigate the relationship between trust and reciprocity. One might predict that trust will be positively correlated with positive reciprocity, to the extent that people use their own positively reciprocal inclinations as the basis for predicting the behavior of others. In this case, someone who is strongly positively reciprocal is more likely to trust, because they predict that their trust will be honored. This could reflect rational use of information or could even reflect the so-called "false consensus effect," such that people overestimate the degree of similarity between others and themselves. On the other hand, it could be that a person's degree of trust in other people is largely unrelated to their own tendency to be positively reciprocal. In our data, we find support for this latter hypothesis. The correlation between trust and reciprocity is only 0.015 , suggesting that people who trust are not necessarily those who are positively reciprocal. Regarding the relationship between trust and negative reciprocity, one might predict a negative correlation. There is evidence that people experience disutility from being betrayed on top of disutility from the resulting loss in income (Bohnet and Zeckhauser 2004). There is also evidence that negative reciprocity is motivated by anger at betrayal (Fehr and Gächter 2002). Thus, people who are negatively reciprocal may be less willing to trust, because they are the people who are most upset by having their trust violated. Our data are consistent with this hypothesis: the correlation between trust and negative reciprocity is -0.113 and significant at the 5\% level.

\section{DETERMINANTS OF TRUST AND RECIPROCITY}

Given that we observe substantial heterogeneity in the degree of reciprocity across individuals, we next turn to an investigation of potential determinants of these individual differences. We investigate the impact on trust and reciprocity of various personal characteristics that are plausibly exogenous to the individual, namely, gender, age, and height. As a second step, we add controls for many other personal characteristics, which are less clearly exogenous, and investigate the robustness of our results. Finally, we also control for personality traits.

Table 1 presents our results from ordinary least square regressions. Standard errors shown in parentheses are robust and allow for correlation of the error term within household. In Columns (1)-(4), the dependent variable is the standardized principal component of the trust questions. Column (1) presents results only for exogenous controls, while Column (2) also includes controls for parental education, family status, number of children, religion, residence in 1989, nationality, occupational and sectoral information, education, and subjective well-being. Columns (3) and (4) repeat this analysis but add psychological traits.

The results indicate that women tend to trust more than men. We also find a somewhat weaker effect of age, such that older persons trust more. Interestingly, height is associated with greater trust. These results are robust and almost unchanged across the different specifications. In Columns (3) and (4), we also find significant effects of personality traits, which improve the explanatory power of the regression substantially. Individuals who are more conscientious, or more neurotic, trust less, as might perhaps be expected. On the other hand, individuals who are more agreeable or more open to experiences tend to trust more. Only extraversion has no significant effect on trust. ${ }^{9}$

Turning to the results for positive reciprocity in Columns (5)-(8), we find that women and the elderly are more inclined to be positively reciprocal, similar to our findings on trust. Interestingly, in contrast to the results for trust, including the psychological traits has an impact on the effect of gender: controlling for personality type, women are less positively reciprocal than men. All personality measures have a significant and positive impact in the regressions for positive reciprocity. The size of the point estimates indicates that conscientiousness and agreeableness have the biggest impact, whereas neuroticism has the smallest impact, which again seems reasonable.

Results in Columns (9)-(12) reveal a fairly different picture with respect to the determinants of negative reciprocity. We consistently find a negative gender effect in all specifications, implying that women are less negatively reciprocal than men. Older persons also tend to be less negatively reciprocal, while height has no effect. In Columns (11) and (12), we

9. Coefficients for all control variables in Table 1 are available in our working paper, Dohmen et al. (2006). 


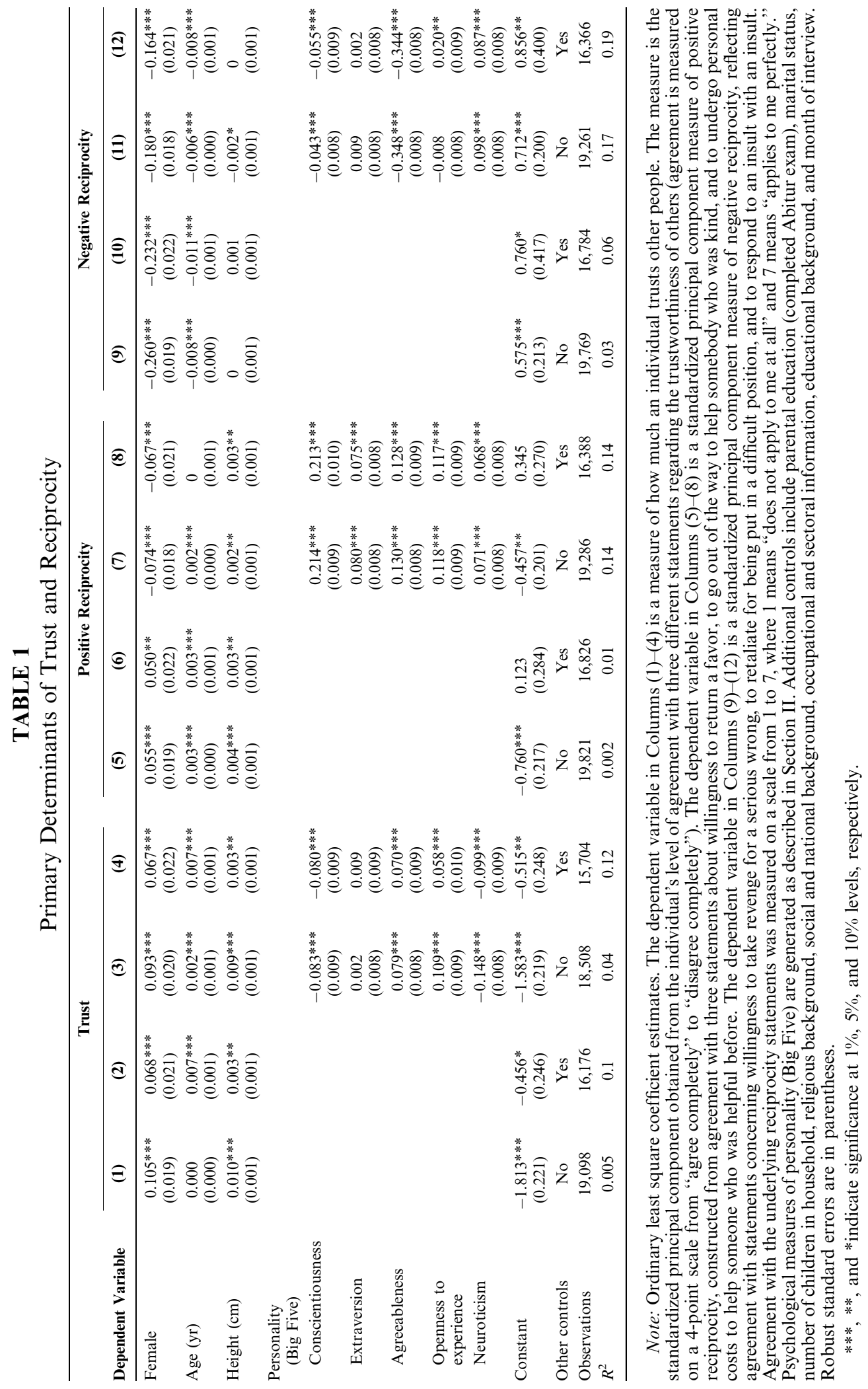


find that more conscientious and more agreeable persons tend to be less negatively reciprocal. On the other hand, individuals who display higher levels of neuroticism tend to be more negatively reciprocal. Extraversion and openness to experience have no effect. Notably, the different impact of determinants for positive and negative reciprocity reinforces the impression that these are distinct traits.

\section{CONCLUDING REMARKS}

This paper is the first to use a large, representative survey to study simultaneously what are generally understood to be the three crucial components of "social preferences": trust, positive reciprocity, and negative reciprocity. The data allow us to provide the first largescale survey evidence on the prevalence of positive and negative reciprocity and to explore how these traits are correlated with each other. We also study the determinants of these social preferences, taking advantage of the variation and statistical power provided by our representative data set. Finally, we provide initial evidence on how psychometric measures of personality type map into measures of social preferences. In addition to contributing to the understanding of social preferences, our findings call for an investigation of the economic consequences of reciprocity, for example, for labor relations and social policy issues. To pick just one example, the presence of negatively reciprocal types tends to make policies that reward people independent on their contribution to society less politically feasible and tends to strengthen support for policies that account for reciprocal considerations. Differences in social preferences may also help to better understand gender or age-specific (labor) market outcomes. For example, negatively reciprocal people can credibly threaten to retaliate and to sanction unfair or uncooperative treatments. This may be a strategic advantage in bargaining, at the workplace and in social interactions in general. Our results suggest that men and younger people have a comparative advantage in this respect.

\section{REFERENCES}

Abbink, K., B. Irlenbusch, and E. Renner. "The Moonlighting Game: An Experimental Study on Reciprocity and Retribution." Journal of Economic Behavior and Organization, 42, 2000, 265-77.

Alesina, A., and E. Ferrara. "Who Trusts Others." Journal of Public Economics, 85, 2002, 207-34.

Bellemare, C., and S. Kröger. "On Representative Social Capital." European Economic Review, 51, 2006, 183-202.

Bohnet, I., and R. Zeckhauser. "Trust, Risk and Betrayal." Journal of Economic Behavior and Organization, 55, 2004, 476-84.

Camerer, C. Behavioral Game Theory. Princeton, NJ: Princeton University Press, 2003.

Dohmen, T., A. Falk, D. Huffman, and U. Sunde. "Homo Reciprocans: Survey Evidence on Prevalence, Behavior and Success." IZA Discussion Paper 2205, 2006.

Falk, A., and U. Fischbacher. "A Theory of Reciprocity." Games and Economic Behavior, 54, 2006, 293-315.

Fehr, E., U. Fischbacher, B. V. Rosenbladt, J. Schupp, and G. G. Wagner. "A Nation-Wide Laboratory: Examining Trust and Trustworthiness by Integrating Behavioral Experiments into Representative Surveys." mimeo, Institute for Empirical Research in Economics, University of Zurich, 2003.

Fehr, E., and S. Gächter. "Altruistic Punishment in Humans." Nature, 415, 2002, 137-40.

Fehr, E., and K. Schmidt. "A Theory of Fairness, Competition, and Cooperation." Quarterly Journal of Economics, 114, 1999, 817-68.

Gerlitz, J.-Y., and J. Schupp. "Zur Erhebung der BigFive-basierten Persönlichkeitsmerktmale im SOEP." DIW Research Notes 4, 2005.

Goldberg, L. R. "The Development of Markers for the Big-Five Structure." Psychological Assessment, 4, 1992, 26-42.

Heckman, J., J. Stixrud, and S. Urzua. "The Effects of Cognitive and Noncognitive Abilities on Labor Market Outcomes and Social Behavior.' Journal of Labor Economics, 24, 2006, 411-82. 